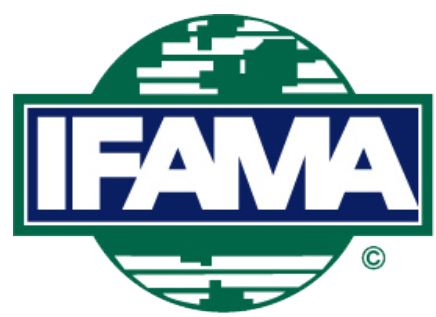

International Food and Agribusiness Management Review

Volume 25, Issue 1, 2022; DOI: 10.22434/IFAMR2020.0124

Received: 30 July 2020 / Accepted: 7 May 2021

\title{
Impact of buyers' support on farmer performance and investments in the Brazilian pork supply chain
}

\section{RESEARCH ARTICLE}

\author{
Franco Müller Martins ${ }^{\circledR a}$, Jacques Trienekens ${ }^{\mathrm{b}}$ and Onno Omta ${ }^{\mathrm{c}}$ \\ ${ }^{a}$ PhD, researcher, Embrapa Suínos e Aves, BR 153, Km 110. Cx. Postal 321, CEP 89. 715-899, SC Concórdia, Brazil \\ ${ }^{b}$ Professor, ${ }^{c}$ Emeritus professor, Business Management \& Organisation Group, \\ Wageningen University \& Research, Hollandseweg 1, 6706 KN, Wageningen, the Netherlands
}

\begin{abstract}
This paper analyses how the technical and managerial support of buyers affects the performance and investment capacity of Brazilian pig farmers. The paper also analyses the influence of the farmers' investment capacity on their own performance and how that performance in turn influences the investment requirements demanded by buyers. We developed a structural equation model applied to a sample of 199 farmers including piglet farmers $(\mathrm{n}=91)$ and finishers $(\mathrm{n}=108)$ working under production contracts. The model includes two constructs that assess performance - financial performance and production and quality performance. The results show that buyer support positively influences both performance constructs and investment requirements for piglet farmers and finishers. The relationship between buyer support and investment capacity was significant only in the sample of finishers. Farmers' investment capacity positively influences both performance constructs in the sample of piglet farmers. For finishers, investment capacity influences only financial performance. Moreover, only production and quality performance of finishers influences investment requirements. The results provide buyers and farmers with insights for refinements in support policies and management.
\end{abstract}

Keywords: Brazil, contracts, coordination, pork chain, performance JEL code: D30, C24, L220

\footnotetext{
(i)Corresponding author: franco.martins@embrapa.br
} 


\section{Introduction}

Increasing societal and consumer demands, both national and international, towards food quality and safety, and increasing competition have led food chains to move from a cost only view to a cost and quality view. Facing these challenges, many food chains use complex contracts as a means to meet strict quality requirements at competitive costs (Dries, 2015; Gellynck and Molnar, 2009; Key and McBride, 2008; Otuska et al., 2016; Swineen and Maertens, 2007).

Several studies have demonstrated that the services that buyers provide in contractual relationships improve farmers performance on productivity, profits and quality (Bellemare, 2010; Briones, 2015; Coronado et al., 2010; Dries et al., 2009; Key and MacBride, 2008; Mishra et al., 2016). Literature has also explained how contracts may enable farmers to access resources to make investments addressing transaction requirements (Dries et al., 2009; Falkowski, 2012; Key and McBride, 2003).

In Brazil, vertical coordination by means of contracts between buyers and farmers is the predominant arrangement to support swine production. Brazil is the fourth largest global producer and exporter of pork. Between 2015 and 2019 it produced on average 3.74 million tons of pork per year. In the same period the country exported an average of 770,000 tons per year (USDA, 2019). The average shares in global production and exports were, respectively, 3.39\% and 9.21\%. Southern Brazil maintains the biggest share of domestic production with $69 \%$ of slaughtered heads (ABPA, 2019). Other important regions are the southeast (16.0\%) and mid-west (14.5\%). The main types of buyers are investor-owned firms (IOFs) and cooperatives (Coops). These companies maintain slaughterhouses for pigs and deliver pork in the domestic market and overseas. IOFs and Coops coordinate more than $80 \%$ of the Brazilian swine production. A minor part of contracted production is held by mini-integrations (MIs). These organizations use contracts with small farmers to obtain live pigs. The main costumers of MIs are other farmers, local slaughterhouses, IOFs and Coops that use MIs to complement their supply (i.e. to handle market fluctuations).

In most contracts used in Brazilian swine production, buyers support farmers with technical assistance and management practices, credit arrangements and, in many cases, inputs. Through these mechanisms buyers also monitor practices and facilities to check their compliance with quality requirements ${ }^{1}$ (Martins et al., 2017a; Miele and Waquil, 2007). The production is usually arranged in distinct stages - production of piglets, nursery and finishing - and conducted by specialized farmers, resembling arrangements used, for instance, in the USA (Key and McBride, 2008; Martinez, 2012).

These vertically coordinated schemes have enabled the Brazilian processors and farmers to adopt modern production technologies and force chain actors to improve their agricultural practices and industrial processes to meet costumer and consumer preferences (De Barcellos et al., 2011). However, the players in this sector face fierce competition and increasing consumer demands (e.g. product quality, food safety, welfare, sustainable practices). Such improvements are crucial in enabling the whole supply chain to maintain and enhance its access to high quality markets. To respond to these challenges, buyers need to increase their collaboration with farmers, focusing on extension services, providing the right quality inputs and supporting farmers in investing in production improvements. Therefore, understanding how buyers' support influences the investments and performance of farmers enables chain actors to develop strategies to improve the quality, production efficiency and competitiveness of the Brazilian pork supply chain.

Studies addressing vertical coordination in the Brazilian pork chain (BPC) have used descriptive approaches to explain the clauses included in the main types of contracts used in this supply chain (Miele and Waquil,

\footnotetext{
${ }^{1}$ These mechanisms differ from those used by important global pork producers in Europe. In countries such as the Netherlands and Germany, pig farmers are independent - i.e. responsible for the inputs and processes used to produce pigs - and contract technical assistance on their own. Sector certification schemes are responsible for monitoring quality at farm level and farmers deliver pigs to slaughterhouses through market mechanisms (Bahlmann and Spiller, 2009; Schulze et al., 2007; Wever et al., 2010). Therefore, unlike these supply chains, in Brazilian pork chains buyers try to directly influence the agricultural practices, facilities and production technologies used by pig farmers.
} 
2007) and to analyse the alignment between quality requirements and coordination mechanisms used to arrange buyer-farmer transactions (Martins et al., 2017a). More recently, Martins et al. (2019) analysed the impact of vertical and horizontal coordination mechanisms on farmer performance. However, literature still lacks studies analysing the impact of buyers support on farmer investments and performance in the BPC.

The present paper analyses, for the Brazilian pork supply chain, how buyers, through technical and managerial support may impact on farmers' investment behaviour and performance. The study contributes several theoretical insights. Firstly, the paper analyses how support services influence requirements that buyers set during the contractual relationship. Secondly, the paper assesses the relationships between buyers' support, farmer investments and farmer performance using a single structural model. This approach allows for an integrated analysis of different aspects concerning the influence of support policies and, therefore, provides in-depth insights on how these policies influence farmer investments and performance. Thirdly, the variable technical and managerial support includes different items concerning support mechanisms identified in literature and used in contracts in the BPC. Compared to previous studies, it provides a much more refined set of items which enables more precise identification of which mechanisms may be improved in support policies. Fourthly, testing the model in two subsamples - of finishers and piglet farmers - provides insights on how different buyer support mechanisms may influence farmer investments and performance. Finally, the examination of these relationships provides buyers and farmers with useful insights into how to improve and further specify support policies and directions for farmer investments.

The remainder of this paper is organized as follows. Section 2 presents the theoretical framework and the hypothesis statement. Section 3 describes the research methods. Section 4 depicts and discusses the results. Section 5 presents the conclusions, limitations and implications for theory and management.

\section{Theoretical framework}

Transaction Cost Economics (TCE) is the theoretical approach used to explain how chain actors choose governance structures (GSs) to facilitate coordination of production and supply. This theory is concerned with identifying the GSs that most efficiently align with the transaction attributes - asset specificity, uncertainty and frequency (Williamson, 1991).

Asset specificity refers to investments that a chain actor makes to fit specific requirements set in a particular agreement. By definition, specific assets lose their value when used in another relationship (Hobbs and Young, 2000; Williamson, 1991). In pork supply chains, for instance, buyers that are more stringent on quality require farmers to make specific investments in certain technologies (e.g. group housing, acclimatisation) and facilities (e.g. sheds, biosecurity) and set incentives for farmers to comply with these requirements.

Uncertainty refers to factors that may affect the performance of the exchange. Transaction parties may face environmental and behavioural uncertainties. Environmental uncertainty refers to unanticipated changes in external factors that surround the transactions and raise the transaction costs of adaptation and coordination (Ghosh and John, 1999; Rindfleisch and Heide, 1997; Williamson, 2008). Examples of environmental uncertainty in the food sector are changing customer requirements and information on quality (Martinez, 2012), market conditions (Heyder et al., 2010), and public regulations and their enforcement (Ménard and Valceschini, 2005; Williamson, 2008; Zylbersztajn and Farina, 1999). Behavioural uncertainty pertains to difficulties in monitoring the performance of a transaction party. Monitoring difficulties arise, for instance, in transactions in which buyers set quality requirements that cannot be verified in inspections.

The frequency of a transaction is important because the replication of a transaction over time facilitates coordination by inducing mutual learning, enhancing reputation and reducing opportunistic behaviour between buyers and suppliers (Williamson, 1991). 
There are three general types of GSs under which chain actors may arrange their transactions: markets, hierarchies and hybrids. Markets are used in transactions where the attributes present low intensity - i.e. relationships in which participants do not share resources and are not required to make specific investments, there are no behavioural or environmental uncertainties and the transactions are executed occasionally (low frequency). In other words, transactions with these characteristics can be easily coordinated by market prices (Wever et al., 2010; Williamson, 1991). In the BPC, a small part (roughly 10\%) of swine production is delivered through spot markets. In these cases, the pigs are produced by independent farmers complying with baseline quality requirements (i.e. public regulations). The main costumers in these transactions are local slaughterhouses and middlemen. Big processors may also purchase pigs or piglets in the spot market to handle market fluctuations (Martins et al., 2017a,b).

Hierarchies (i.e. vertical integration) are applicable to coordinate a transaction with high asset specificity, high levels of uncertainty and frequency. By using hierarchies, a firm exerts absolute control on resources and processes that are used to produce goods or inputs. These GSs enable chain actors to handle disturbances in transactions (e.g. quality, volume) within the boundaries of the firm (Wever et al., 2010; Williamson, 1991). In the BPC, hierarchies are rarely used in transactions concerning commercial pigs. Some companies, such as big IOFs and cooperatives maintain breeding farms to raise the sows to be used in their production chains by the contracted farmers. More recently, some companies are implementing central farms, which are totally managed by their technical staff, to cover part of their supply of piglets. This strategy aims to increase sanitary control in the supply chain and reduce logistics costs.

Hybrids are GSs used to handle a certain degree of asset specificity and uncertainty in transactions in which parties have mutual commitments on resources and processes (Ménard, 2004). Contracts are typical hybrid GSs used to arrange transactions between farmers and processors in food supply chains. Through contracts, parties establish clauses and incentives related to resources, processes, quality standards and volumes to which they commit in a transaction (Wever et al., 2010). Processor and retailers use contracts to control and differentiate in quality and to ensure participation in global markets (Dries et al., 2009; Swineen and Maertens, 2007). Farmers, in turn, enter contracts to handle production and market risks, to safeguard investments and to access resources and technology (Dries, 2015; Key and McBride, 2008).

\subsection{Contracts in the Brazilian pork supply chain}

In the BPC chain actors typically arrange pig production in distinct stages - piglet production, nursery and finishing - assigned to specialised farmers. There are two types of farms used to produce piglets - weaning and farrowing farms. Weaning farms produce and raise piglets until they reach $7-8 \mathrm{~kg}$. In farrowing farms piglets are born and raised until reaching $24-25 \mathrm{~kg}$. Nursery farms receive the weaned $(7-8 \mathrm{~kg})$ piglets and raise them until they reach $24-25 \mathrm{~kg}$. Finishing farms receive piglets from farrowing or nursery farms and raise them until they reach the slaughtering weight (125-130 kg). Basically, chain actors use three types of contracts, all including technical and managerial support, to arrange the supply of pigs. These contracts are known as 'buying and selling', 'loan' and 'partnership' (Martins et al., 2017a,b; Miele and Waquil, 2007). The 'buying and selling' contracts are agreements used in transactions with piglet farmers that use the main inputs (i.e. feed and sows) that they themselves produce or provide. However, these inputs must meet standards that the buyers set. The base prices are based on markets. The buyers add a bonus based on the quality of the piglets (i.e. weight uniformity). Formally, the volumes that are delivered (number of piglets per batch) are subject to short term variations. However, farmers usually deliver regular volumes during the contractual relationship.

In 'loan' contracts, the buyer provides the piglet farmer with the sows used to produce the piglets. The farmer produces or purchases feed which meets the standards required by the buyers. The main criterion used to set base prices is the productivity that the farmers obtain with the sows with which they are provided (i.e. number of raised piglets per sow). In some cases, buyers add a bonus based on compliance with quality requirements (e.g. facilities, documentation and the piglets). The volumes are fixed for an indefinite time - i.e. the contractual term. 
'Partnership' contracts are used to arrange transactions with piglet farmers, nursery farmers and finishing farmers. In these contracts, buyers provide farmers with the animals (i.e. sows or piglets) and the feed to be used in production. Buyers that use these contracts, especially firms and cooperatives, usually maintain feed mills and/or breeding farms to produce the main inputs. Therefore, these buyers use their own production costs and productivity indexes as references to set (internal) payment prices for farmers. For piglet farmers the main indexes are the number of piglets raised per sow and feed conversion. For nursery and finishing farmers the main indexes are feed conversion and mortality. Moreover, buyers usually add a bonus based on compliance with specific quality requirements. The volumes are fixed indefinitely.

The mechanisms explained above demonstrate how the contracts used in Brazilian swine production fit the classical transaction attributes. Buyers such as IOFs and big cooperatives invest in feed mills, genetic programs and breeding farms. Farmers, in turn, invest in facilities and equipment meeting specific requirements of these buyers. Therefore, contracts are the GSs used to protect the specific investments made by both parties. Furthermore, by providing farmers with technical and administrative support, which includes monitoring processes and facilities, buyers handle uncertainties related to quality compliance. This control is stricter in loan and partnership contracts whereby the buyers provide farmers with inputs. Finally, addressing the attribute of frequency, the contracts used in the BPC facilitate coordination by ensuring a regular supply of piglets and finished pigs.

As mentioned above, contracts are hybrid governance structures in which participants have a certain degree of mutual dependence. To represent the level of control that parties exert on resources and processes used in their transactions, TCE scholars use a continuum with governance structures ranging between market and hierarchy (Gellynck and Molnar, 2009; Raynaud et al., 2005; Schulze et al., 2007). Figure 1 represents the continuum of governance structures used in the BPC. Partnership is the contract which is closest to vertical integration. Compared to the other kinds of contract, in a partnership buyers allocate more resources that they themselves produce and use internal prices. Loan contracts, under which buyers allocate only the animals, assume an intermediary position. The buying and selling contract, under which buyers provide only support services and use market prices is the least integrated kind of contract. Other GSs used in the BPC account for the extremes A very small part of the BPC does not work with contracts and uses spot markets. Central piglet farms and breeding farms owned by processors represent vertical integration.

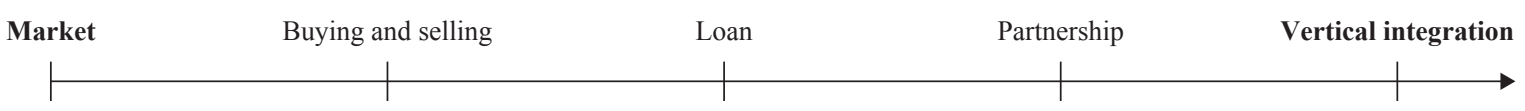

Figure 1. Contractual arrangements used in the Brazilian pork chain.

\subsection{Hypothesis}

Various studies have demonstrated that buyers that include service provision in contracts have helped farmers to improve their performance. In the US pork sector Key and MacBride (2008) found that contracts which include the provision of high-quality inputs and knowledge improved the productivity of hog farmers. Briones (2015) demonstrated that technical assistance, high-technology inputs and credit provided by buyers improved the productivity and the profits of farmers in the Philippine tobacco industry. Contracts including similar mechanisms have been shown to increase the profits of paddy seed producers in Nepal (Mishra et al., 2016). In Europe, services provided by processors have enabled dairy farmers to access knowledge and technologies to improve productivity and quality (Dries et al., 2009). Likewise, extension services have increased the productivity of fruit producers in Madagascar (Bellemare, 2010). In the Mexican avocado sector, buyer-farmer information exchange has enabled farmers to improve efficiency and product quality (Coronado et al., 2010). Thus, our first hypothesis is: 
H1: There is a positive relationship between buyers' technical and managerial support and farmer performance in the Brazilian swine production.

Buyers may use contracts to require their suppliers to make specific investments. Because these requirements increase as the contractual specificity increases (Hobbs and Young, 2000; Williamson, 2010), buyers may support farmers in their projects related to these investments. In the pork sector buyers commonly specify facilities (sheds, structures for manure management and biosecurity) and technologies (genetics, acclimatisation) that farmers use to produce pigs. The buyers often assist farmers in obtaining credit for these investments and, during the contractual relationship, make regular farm visits to monitor compliance and provide farmers with technical assistance (Key and McBride, 2003; Martinez, 2012; Martins et al., 2017a). Therefore, this assistance may also include recommendations on investments. Likewise, Dries et al. (2009) found that dairy processors in Eastern Europe supported farmers with credit arrangements to facilitate their investments meeting (the buyers') specific requirements on production technologies and quality. Kresting and Wollni (2012), found that the use of quality management systems to monitor compliance was determinant in enabling Thai producers to adopt the GlobalGap standards. Furthermore, through technical visits or training programs, buyers may inform famers on investments that may be required in the near future (Coronado et al., 2010) based on information on food regulations and developments in production technologies. Therefore, one may expect that support offered by buyers is related to investments that are required to comply with current and future transaction requirements. Hence, our second hypothesis is:

H2: There is a positive relationship between buyers' technical and managerial support and expected investment requirements in the Brazilian swine production.

Food companies continuously upgrade their standards to respond to food regulations and consumer preferences. Moreover, competition on costs drives these companies to source from a selected number of efficient and high compliance farmers. Therefore, farmers need investment capacity to efficiently meet buyer requirements. Buyers may use different means to improve farmer investment capacity. For instance, providing the farmer with a buyer-approved project of facilities to be used in production may facilitate access to credit from financial agents (Falkowski, 2012; Key and McBride, 2003). In eastern and central Europe, processors have used credit programs and loan guarantees to enable farmers to make investments to improve milk quality (Dries et al., 2009). Finally, because the support of buyers improves the financial performance attained by farmers (Briones, 2015; Kresting and Wollni, 2012), it may also enable farmers to access resources to make investments. Thus, our third hypothesis is:

H3: There is a positive relationship between buyers' technical and managerial support and farmer investment capacity in the Brazilian swine production.

Investments in production factors are crucial to enable farmers to improve performance. For example, Key (2013) found that credit access allowed U.S. hog farmers to expand production and to increase efficiency and profits. Investments in modern equipment and management systems enabled Swedish pig famers to reduce labour costs and improve efficiency on fixed and variable inputs (Labajova et al., 2016). Looking at different agricultural productions, Grande et al. (2011) found that financial position was of key importance in allowing Norwegian farmers to make investments leading to improvements in market share and sales growth. Lu et al. (2010) found a positive relationship between the investments of Chinese vegetable farmers in buyers' specific requirements and their performance on quality. Likewise, Handschuch et al. (2013) demonstrated that farmers who could afford the costs related to adopting international food standards improved their quality compliance and income in the Chilean raspberry sector.

H4: There is a positive relationship between farmers' investment capacity and their performance in the Brazilian swine production. 
In buyer-farmer contracts, prior to production the buyers specify the agricultural practices and often the facilities and equipment that farms must use to meet the transaction requirements (Dries, 2015; Key, 2013; Otsuka et al., 2016). During the contractual relationship, buyers monitor processes, facilities, information on quality compliance and productivity. Based on this information, buyers provide farmers with advice on how to improve their performance (Bellemare, 2010; Bellemare and Bloem, 2018). Thus, it could be suggested that buyers may use this advice to require farmers to make investments to improve their production. Thus, our fifth hypothesis is:

H5: The lower the farmer performance, the higher the investment requirements are set by buyers in the Brazilian swine production.

The following section explains the methods used to test the research model (Figure 2).

\section{Methods}

\subsection{Data collection}

Data were obtained using a survey questionnaire applied to 199 pig farmers ${ }^{2}$ in southern Brazil. The companies established in this region accounted for $69.6 \%$ of slaughters in the BPC (ABPA, 2019). The farmers were randomly selected from lists provided by their buyers. The sample includes finishers $(\mathrm{n}=108)$ and piglet farmers $(\mathrm{n}=91)$ with contracts including technical and managerial support ${ }^{3}$. The subsample of piglet farmers included 60 farmers using their own sows and feed. The other 31 farmers used sows and feed provided by their buyers. Semi-structured interviews $(n=41)$ addressed to chain actors (e.g. representatives of slaughterhouses, government, farmers associations, slaughterhouses associations, feed stuff suppliers, retailers, information technology company) covering topics such as chain coordination, quality requirements and performance, were carried out to support the design of the research model and the survey questionnaire. The survey questionnaire was applied in face-to-face interviews between March 2015 and May 2015. Each farmer answered the questionnaire assessing his/her relationship with a single buyer.

\footnotetext{
${ }^{2}$ A preliminary analysis of the data shows that farms in all contexts vary in size. In addition, a bivariate correlation analysis demonstrated that size is not correlated to most of the measurement items used in the model. Therefore, farm size was not included as a control variable.

${ }^{3}$ The contracts between buyers and nursery farmers include the same coordination mechanisms used in contracts with finishers. Moreover, in pork chains, the number of nursery farms is limited when compared to the number of finishers and piglet farmers. Therefore, to facilitate the research design and the data collection, nursery farmers were not included in the sample.
}

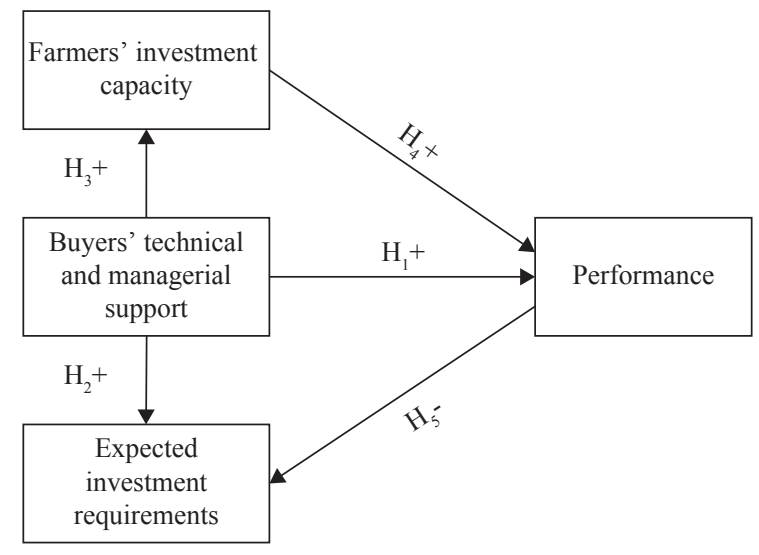

Figure 2. Hypotheses tested in the research framework. 


\subsection{Measurement}

The research model includes 21 items to represent the measures of the constructs of technical and managerial support, investment capacity, expected investment requirements, financial performance, and production and quality performance. All measures (Table 1) used a seven-point Likert scale ranging from 'strongly disagree' (value $=1$ ) to 'strongly agree' (value $=7$ ). The measurement items were selected from literature and refined with information obtained in the semi-structured interviews with chain actors.

As regards the literature, papers were sought on the Scopus, Web of Science and Google Scholar platforms. We used key words related to the influence of variables related to contractual relationships (e.g. contracts, vertical coordination, buyers support) on farmers' performance and investments (e.g. investment capacity, investment requirements, access to capital). We prioritised studies on contract farming that used quantitative approaches to analyse how contracts or services provided by buyers influence farmers' performance and investments. We found few studies examining buyer support and farmer performance and investments in the pork sector. Therefore, we selected and adapted various items from studies examining buyer-farmer relationships in other food sectors.

The construct buyers' technical and managerial support includes six items. The first pertains to support in credit obtainment. Various studies have made it clear that buyers' support includes credit arrangements. However, these studies do not use Likert scales to assess this support mechanism. Therefore, this item draws on studies that use instrumental variables to explain how buyers support farmers in accessing capital for investments in the pork sector (Key, 2013; Key and McBride, 2003). The second item concerns feedback on information provided by the farmer. Plaggenhoef (2007) used a similar item to assess management practices in different food chains. The item also draws on Coronado et al. (2010) who used a construct with items addressing information exchange on buyer requirements to analyse the performance of avocado farmers in Mexico. The third and the fourth items refer to the organisation of technical meetings and training programs. We failed to find any studies that use a Likert scale for these items. Therefore, the items were selected based on studies that explain how these mechanisms improve farmer performance (Dries et al., 2009; Maertens and Vande Velde, 2017). The fifth item, on technical assistance, consists of the items used to assess farmers' performance in other food chains (Coronado et al., 2010; Lu et al., 2008). The item addressing the use of production manuals provided by buyers is derived from the semi-structured interviews.

The construct investment capacity includes three items related to the farmers capacity to invest in the maintenance of the farm, requirements set by buyers and those set in public regulations. Studies on vertical relationships barely address farmers' perceived investment capacity. Thus, these items drew on answers obtained in the semi-structured interviews and studies that provide insights into farmer investments and performance in the (US) pork sector (Key, 2013) and other food chains (Dries et al., 2009; Lu et al., 2008; Swinnen and Maertens, 2007).

Studies on contractual relationships, which are related to investments, normally use a variable to indicate whether (or not) an actor invests in transaction-specific requirements (Coronado et al., 2010; Lu et al., 2010; Wu et al., 2017). However, these studies do not specify technical items in which farmers need to invest. Therefore, the items belonging to the construct investment requirements drew on the semi-structured interviews. It includes four items regarding investments in technologies that chain actors judged as critical for performance in swine production - acclimatisation of facilities, animal welfare, sanitation, and manure disposal.

The research model includes two constructs that assess performance: financial performance and production and quality performance. As regards financial performance, the items addressing sales and profits are represented by measurements of perceived performance changes used in studies on buyer-farmer relationships in the Chinese vegetable sector (Lu et al., 2008) and the Mexican avocado sector (Coronado et al., 2010). The item on prices drew on statements by chain actors during the semi-structured interviews. The construct Production and quality performance includes five items: two measurements related to mortality and feed conversion, 
which represent important productivity indexes used in swine production and were pointed out in the semistructured interviews; and the other items address farmers' perceptions of quality (Coronado et al., 2010).

\subsection{Data analysis}

The first step of data analysis was testing the validity of the measurement items using SPSS (SPSS Inc., Chicago, IL, USA) (Field, 2013). In this sense, factor loadings were obtained, through varimax rotation, to indicate the strength of the relationship between each measurement item and the construct (Table 1). Factor loadings above 0.708 are recommended (Hair et al., 2019). However, values around 0.5 are also acceptable in studies using adequate sample sizes (Hair et al., 2010). The items BS1 (in the full model and in the finisher model) and BS5 (full model) present the lowest values. However, BS1 presents a more acceptable value in the piglet farmer model. Likewise, BS5 presents better values in the piglet and finisher models. Moreover, BS1 and BS5 refer to support mechanisms typically used in the BPC. For these reasons, although we recognize that results must be interpreted with care, we decided to maintain these items in the three models.

Table 1. Measurement items.

\begin{tabular}{|c|c|c|c|c|c|c|c|c|}
\hline \multirow[t]{2}{*}{ Constructs } & \multicolumn{2}{|c|}{ Measurement items } & \multicolumn{2}{|c|}{ Full sample $(n=199)$} & \multicolumn{2}{|c|}{ Piglet farmers $(n=91)$} & \multicolumn{2}{|c|}{ Finishers $(n=108)$} \\
\hline & & & Loading & $\begin{array}{l}\text { Cronbach's } \\
\text { alpha }\end{array}$ & Loading & $\begin{array}{l}\text { Cronbach's } \\
\text { alpha }\end{array}$ & Loading & $\begin{array}{l}\text { Cronbach's } \\
\text { alpha }\end{array}$ \\
\hline \multirow[t]{6}{*}{$\begin{array}{l}\text { Buyers' } \\
\text { technical and } \\
\text { managerial } \\
\text { support (BS) }\end{array}$} & BS1 & $\begin{array}{l}\text { My main buyer gives me } \\
\text { administrative support to } \\
\text { obtain credit to invest in } \\
\text { my farm. }\end{array}$ & 0.463 & \multirow[t]{6}{*}{0.66} & 0.600 & \multirow[t]{6}{*}{0.70} & 0.331 & \multirow[t]{6}{*}{0.65} \\
\hline & $\mathrm{BS} 2$ & $\begin{array}{l}\text { My main buyer gives us } \\
\text { feedback to improve } \\
\text { quality based on the } \\
\text { information we give } \\
\text { them. }\end{array}$ & 0.554 & & 0.630 & & 0.508 & \\
\hline & BS3 & $\begin{array}{l}\text { My main buyer organises } \\
\text { technical meetings } \\
\text { regularly. }\end{array}$ & 0.754 & & 0.831 & & 0.696 & \\
\hline & BS4 & $\begin{array}{l}\text { My main buyer stimulates } \\
\text { me (or my staff } \\
\text { members) to do training } \\
\text { on production practices. }\end{array}$ & 0.734 & & 0.701 & & 0.767 & \\
\hline & BS5 & $\begin{array}{l}\text { My main buyer gives } \\
\text { technical assistance } \\
\text { whenever I need it. }\end{array}$ & 0.468 & & 0.502 & & 0.512 & \\
\hline & BS6 & $\begin{array}{l}\text { I use a manual on } \\
\text { production practices } \\
\text { provided by my main } \\
\text { buyer. }\end{array}$ & 0.694 & & 0.655 & & 0.733 & \\
\hline \multirow[t]{3}{*}{$\begin{array}{l}\text { Investment } \\
\text { capacity (IC) }\end{array}$} & IC 1 & $\begin{array}{l}\text { I can sufficiently invest in } \\
\text { the maintenance of my } \\
\text { farm. }\end{array}$ & 0.911 & \multirow[t]{3}{*}{0.85} & 0.905 & \multirow[t]{3}{*}{0.86} & 0.915 & \multirow[t]{3}{*}{0.85} \\
\hline & IC 2 & $\begin{array}{l}\text { I can sufficiently invest in } \\
\text { requirements set by my } \\
\text { main buyer. }\end{array}$ & 0.897 & & 0.918 & & 0.886 & \\
\hline & IC 3 & $\begin{array}{l}\text { I can sufficiently invest in } \\
\text { requirements to comply } \\
\text { with public regulations. }\end{array}$ & 0.822 & & 0.827 & & 0.823 & \\
\hline
\end{tabular}


Table 1. Continued.

\begin{tabular}{|c|c|c|c|c|c|c|c|c|}
\hline \multirow[t]{4}{*}{$\begin{array}{l}\text { Expected } \\
\text { investment } \\
\text { requirements } \\
\text { (EIR) }\end{array}$} & ER1 & $\begin{array}{l}\text { I will be required to invest } \\
\text { in new technologies } \\
\text { in acclimatisation, } \\
\text { watering, fans within the } \\
\text { next three years. }\end{array}$ & 0.870 & \multirow[t]{4}{*}{0.83} & 0.838 & \multirow[t]{4}{*}{0.79} & 0.883 & \multirow[t]{4}{*}{0.86} \\
\hline & ER2 & $\begin{array}{l}\text { I will be required to } \\
\text { invest in animal welfare } \\
\text { (group housing) within } \\
\text { the next } 3 \text { years. }\end{array}$ & 0.814 & & 0.794 & & 0.862 & \\
\hline & ER3 & $\begin{array}{l}\text { I will be required to } \\
\text { invest in sanitation of } \\
\text { production processes } \\
\text { within the next } 3 \text { years. }\end{array}$ & 0.843 & & 0.810 & & 0.851 & \\
\hline & ER4 & $\begin{array}{l}\text { I will be required to } \\
\text { improve the disposal of } \\
\text { manure within the next } \\
3 \text { years. }\end{array}$ & 0.756 & & 0.690 & & 0.771 & \\
\hline \multirow[t]{3}{*}{$\begin{array}{l}\text { Financial } \\
\text { performance } \\
(\mathrm{FP})\end{array}$} & FP 1 & $\begin{array}{l}\text { My sales have performed } \\
\text { satisfactorily in the last } \\
\text { three years. }\end{array}$ & 0.805 & \multirow[t]{3}{*}{0.72} & 0.845 & \multirow[t]{3}{*}{0.73} & 0.778 & \multirow[t]{3}{*}{0.71} \\
\hline & FP 2 & $\begin{array}{l}\text { My profits have been } \\
\text { satisfactory over the last } \\
\text { three years. }\end{array}$ & 0.877 & & 0.826 & & 0.904 & \\
\hline & FP3 & $\begin{array}{l}\text { The price I get for the } \\
\text { pigs/piglets is normally } \\
\text { enough to cover the } \\
\text { production costs. }\end{array}$ & 0.718 & & 0.735 & & 0.704 & \\
\hline \multirow[t]{5}{*}{$\begin{array}{l}\text { Production } \\
\text { and quality } \\
\text { performance } \\
\text { (PQ) }\end{array}$} & PQ1 & $\begin{array}{l}\text { The mortality rate on my } \\
\text { farm is lower than the } \\
\text { average found on other } \\
\text { farms. }\end{array}$ & 0.698 & \multirow[t]{5}{*}{0.71} & 0.683 & \multirow[t]{5}{*}{0.69} & 0.709 & \multirow[t]{5}{*}{0.71} \\
\hline & PQ2 & $\begin{array}{l}\text { The feed conversion on } \\
\text { my farm is better than } \\
\text { the average obtained by } \\
\text { other farmers. }\end{array}$ & 0.825 & & 0.739 & & 0.860 & \\
\hline & PQ3 & $\begin{array}{l}\text { My main buyer is satisfied } \\
\text { with the quality of the } \\
\text { pigs I deliver. }\end{array}$ & 0.584 & & 0.633 & & 0.570 & \\
\hline & PQ4 & $\begin{array}{l}\text { My main buyer is satisfied } \\
\text { with the documentation I } \\
\text { send with my deliveries. }\end{array}$ & 0.552 & & 0.643 & & 0.509 & \\
\hline & PQ5 & $\begin{array}{l}\text { I deliver higher quality } \\
\text { than the average pig } \\
\text { producers. }\end{array}$ & 0.729 & & 0.704 & & 0.763 & \\
\hline
\end{tabular}

Afterwards, Cronbach's alpha values (Table 1) were obtained to test the internal reliability of the constructs. Cronbach's alpha values equal or higher than 0.7 are preferable (Hair et al., 2019). Most constructs fit this threshold in three models. The construct BS (in the full model and in the finisher model) and PQ (in the piglet farmer model) present values slightly lower than the preferable Cronbach's alpha. However, these values can be also acceptable (Cho and Kim, 2015). 
The hypotheses were tested in a structural equation model (SEM) using STATA IC 14 (StataCorp LLC, College Station, TX, USA). SEM allows for simultaneously obtaining estimates for all relationships that exist between the constructs included in the model (Lowry and Gaskin, 2014; Tomarken and Waller, 2005). Thus, this technique is suitable to analyse relationships between buyers' support, farmer performance, investment capacity and investment requirements. The model fit (Table 2) was assessed verifying the root mean square of approximation (RMSEA), the normed chi-square (i.e. $\chi^{2} / \mathrm{df}$ ) and the comparative fit index (CFI). According to Hooper et al. (2008), $\chi^{2} / \mathrm{df}$ ranging between 2.0 and 5.0, a RMSEA smaller than 0.08, and a CFI greater than 0.9 are acceptable measures of fit. The model used in the full sample fit these thresholds. The models of finishers and piglet farmers meet the required $\chi^{2} / \mathrm{df}$ and RMSEA but do not fully meet the desired CFI, probably due the reduced sample size. This may imply that results on these subsamples cannot be strongly supported. However, maintaining these models allows for obtaining interesting indications on how differences concerning support mechanisms may influence farmer investments and performance.

\section{Results and discussion}

This section discusses the estimates obtained in the three models tested in the present study. The model was first applied to the full sample (Figure 3) and, subsequently, to the subsamples of piglet farmers (Figure 4) and finishers (Figure 5).

H1: Buyers'technical and managerial support and farmers' performance.

The results demonstrate that technical and managerial support given by buyers improves the financial performance of Brazilian pig farmers in all three models - full sample, piglet farmers and finishers. This outcome is in line with studies demonstrating that the contractual relationships enable farmers to reduce costs and increase their revenues and profits (Briones et al., 2015; Mishra et al., 2016). We also found, in the three models, that buyers' technical and managerial support improves performance in production and quality. This result corroborates Key and McBride (2008) who found that US pig farmers under contractual relationships improved their productivity. Studies in other agricultural sectors provide similar evidence (Bellemare, 2010; Coronado et al., 2010; Dries et al., 2009). These results, therefore, support H1.

\section{H2: Buyers'technical and managerial support and expected investment requirements.}

Technical and managerial support offered by buyers was found to be positively related to expected investment requirements in the three models. This result indicates that support mechanisms such as technical assistance, technical meetings and training provide Brazilian piglet farmers and finishers with information and insights regarding investments that are necessary to meet the requirements of their transactions. Indeed, in the Brazilian pork supply chain, during the contractual relationship, buyers arrange farm visits to provide farmers with technical support and check compliance with requirements related to practices, facilities and technologies (Martins et al., 2017). Based on this check, the buyer may recommend farmers to make improvements or replace resources that do not meet their requirements. Moreover, these buyers normally promote training programs through which farmers may gain insights into market and technology developments and become aware of investments that may be necessary in the (near) future. We have not found previous studies that use a quantitative model to assess the relationship between support given by buyers and investment requirements.

Table 2. Models' fit measures. ${ }^{1}$

\begin{tabular}{lrllllll}
\hline Sample & $\mathbf{n}$ & $\mathbf{X}^{\mathbf{2}}$ & $\boldsymbol{P}\left(\mathbf{X}^{\mathbf{2}}\right)$ & $\mathbf{d f}$ & $\mathbf{X}^{\mathbf{2}} \mathbf{d f}$ & RMSEA & CFI \\
\hline Full (finishers and piglet farmers) & 199 & 291.473 & 0.000 & 71 & 4.11 & 0.055 & 0.910 \\
Finishers & 108 & 292.253 & 0.000 & 71 & 4.13 & 0.076 & 0.850 \\
Piglet farmers & 91 & 254.589 & 0.000 & 71 & 3.59 & 0.067 & 0.860 \\
\hline
\end{tabular}

${ }^{1} \mathrm{CFI}=$ comparative fit index; $\mathrm{df}=$ degrees of freedom; RMSEA = root mean square of approximation. 
However, this finding is in line with studies indicating that buyers use their support to communicate quality requirements to farmers (Dries et al., 2009; Key, 2013; Kresting and Wollni, 2012). Therefore, H2 can be supported.

\section{H3: Buyers'technical and managerial support and farmer investment capacity.}

The relationship between buyers' technical and managerial support and investment capacity was positive in the model for the full sample and that for finishers. This suggests that administrative support to facilitate credit arrangements and mechanisms used to improve production (e.g. technical assistance; feedback on performance) enable these farmers to make a more efficient resource allocation and access resources to make investments. As such, this finding is in line with Key and McBride (2003), who found that farmers in contractual relationships, compared to farmers who deliver to the spot markets, have a greater capacity to make investments in productive technologies. Studies looking at the role of vertical coordination in dairy production in eastern Europe provided similar evidence (Dries et al., 2009; Falkowski, 2012).

Contrary to literature (Dries, et al., 2009; Falkowsky, 2012), the relationship between buyers' support and investment capacity was not significant in the model of piglet farmers. Curiously, the mean scores (Supplementary Table S1) indicate that piglet farmers perceive their investment capacity as good and recognise that buyers provide them with support services (e.g. credit, feedback on quality, technical assistance). This may be explained by differences concerning resource allocation that exist under contracts used in piglet production and finishing. As explained above, in the BPC, in all contracts with finishers, buyers provide farmers with the main inputs. In piglet production, in turn, contracts that foresee the provision of inputs are prevalent. However, there are also contracts whereby farmers use their own feed and sows. In the present study, most sampled piglet farmers $(n=60 / 91)$ use this type of contract. Feed and sows are inputs of great impact on production costs. Therefore, it may be possible that the farmers' expenditures on these inputs overshadow their perception of how the support services impact their investment capacity. However, further research into how differences concerning resource allocation influence farmer investment capacity is needed to confirm this assumption. Considering the outcomes obtained in the three models, the hypothesis $\mathrm{H} 3$ can be partially supported.

\section{H4: Farmer investment capacity and farmer performance.}

The results obtained in the full sample indicate that the investment capacity of Brazilian pig farmers improves their financial performance. This outcome is in line with Key (2013) who demonstrated that US pig farmers who accessed capital to invest in production improved their efficiency and profits, and corroborates studies carried out in other agricultural sectors (Grande et al., 2011; Labajova et al., 2016). Unlike previous studies (Handschuch et al., 2013; Lu et al., 2010) the results indicate that investment capacity does not influence performance in production and quality. In the piglet farmer model, we found that the farmers' investment capacity improves both performance constructs, supporting the literature. However, in the finisher model H4 holds only for financial performance (Grande et al., 2011; Key, 2013). This suggests that finishers do not perceive that investment capacity influences their performance in production and quality. This contradicts studies that relate buyers' transaction-specific investments to improvements in quality (Handschuch et al., 2013; Lu et al., 2010). As explained above, Brazilian finishers are provided with the piglets and feed. Therefore, these farmers do not spend resources and time to produce or improve processes to obtain these inputs. For this reason, it may be possible that finishers have a greater focus on their financial performance and only relate investment capacity to revenues and profits. Thus, these farmers would only perceive the influence of investment capacity on productivity and quality if they indeed invested to improve these aspects. Yet, they would only invest if required by their buyers. However, further research would be needed to confirm these assumptions. These results partially support $\mathrm{H} 4$. 


\section{H5: Farmer performance and expected investment requirements.}

In the full sample the relationship between expected investment requirements and farmers' financial performance was not significant. Indeed, farmers' revenues and profits do not inform buyers on areas in which farmers should invest to improve their production. However, the results show that investment requirements and production and quality performance are negatively related and support the literature (Bellemare and Bloem, 2018; Dries, 2015; Otsuka et al., 2016). Looking at the subsamples, both performance indicators have not presented a significant relationship with investment requirements in the piglet farmer model. In the finisher model, in turn, only performance in production and quality was (negatively) related to expected investment requirements. Therefore, once again, the results obtained in the full sample may be due to differences concerning the support provided under the contracts of piglet farmers and finishers.

Regarding piglet farmers, the mean scores suggest that farmers recognise the need to make investments (Supplementary Table S1). Considering that for most the surveyed piglet farmers the buyers do not provide feed and sows, it may be possible that buyers are not concerned with the productivity and quality that these farmers obtain. In addition, it may be possible that these farmers, compared to those provided with inputs, develop more awareness of the investments they need to make. However, further research would be needed to confirm these assumptions.

We have not found any previous studies that assess the influence of farmer performance on investment requirements. However, the results obtained in the model of finishers suggest that, in the BPC, buyers use information on productivity and quality obtained through in-farm technical visits (Martins et al., 2017a) to decide on requirements for farmers. This outcome resembles studies on the role of buyers in requiring farmers to meet transaction requirements (Bellemare, 2010; Dries 2015; Otsuka et al., 2016). H5 is, therefore, partially supported.

\section{Conclusions and implications}

This paper examined how technical and managerial support offered by buyers affects the performance, investment capacity and investment requirements of Brazilian pig farmers. In addition, the paper examined how farmers' investment capacity and investment requirements set by buyers relate to the farmers' performance. The results demonstrate that, in general, buyers' technical and managerial support improves pig farmers' performance and investment capacity and influences the investment requirements imposed on them. However, the results obtained in the subsamples (Table 3) suggest that some influences may depend on the type of buyer-farmer relationship regarding, in particular, differences in terms input provision.

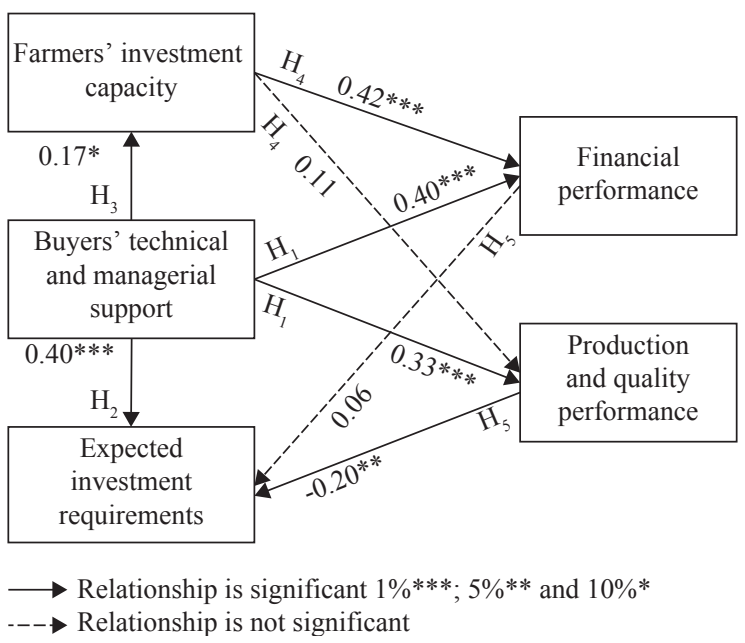

Figure 3. Estimates in the full sample. 


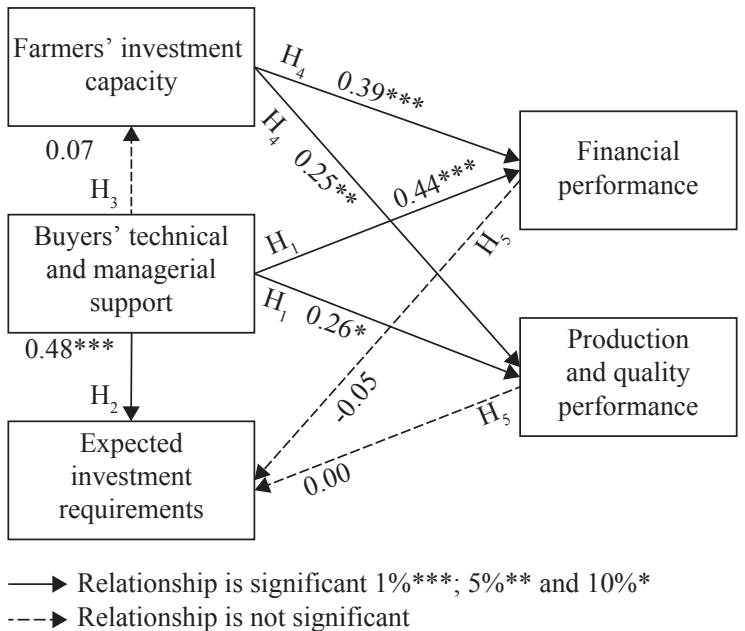

Figure 4. Estimates in the sample of piglet farmers.

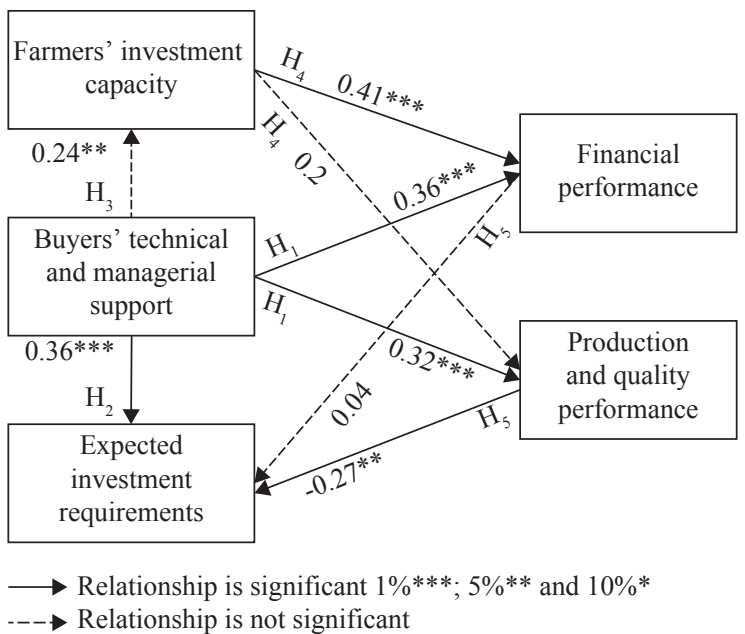

Figure 5. Estimates in the sample of finishers.

Table 3. Results of the hypotheses tests. ${ }^{1}$

\begin{tabular}{lcllll}
\hline Hypotheses & Independent variables & Dependent variables & Full sample & Piglet farmers & Finishers \\
\hline H1 & Buyers' technical and & Performance & Supported & Supported & Supported \\
H2 & managerial support & Investment Requirements & Supported & Supported & Supported \\
H3 & & Farmer investment capacity & Supported & Not supported & Supported \\
H4 & Farmer investment & Performance & Partially supported & Not supported & Partially supported \\
& capacity & & & & \\
H5 & Performance & Investment requirements & Partially supported & Not supported & Partially supported \\
\hline
\end{tabular}

${ }^{1}$ Supported $=$ the relationship is significant at 1,5 or $10 \%$; not supported $=$ the relationship is not significant.

\subsection{Theoretical implications}

The paper contributes several new insights into TCE theory. Firstly, examining the influence of technical and managerial support offered by buyers and the farmers' performance on investment requirements provides insights into the requirements that buyers set during the contractual relationship. In our view, this is a new perspective in terms of the literature on buyer-farmer contracts, as most studies focus on investments that buyers 
set before production begins. Secondly, the paper uses a single model to examine the relationships between buyers' support, farmers' investments and performance. Most previous contributions used the existence of a contract or a type of support service as independent variables to assess its impact on farmers' performance (Bellemare, 2010; Briones, 2015; Key and Mc Bride, 2008; Mishra et al., 2016) or investments (Falkwosky, 2012; Key, 2013). Moreover, these studies look at the relationships between contracts and performance and between contracts and investments separately. Therefore, the present paper provides additional insights into the interaction effects of investments and performance and gives a steer on buyers' support policies.

Thirdly, the study uses a construct including items referring to different types of services. This refines insights into support mechanisms provided by buyers as most studies examining the influence of contracts and/or extension services on farmers' performance do not disentangle the independent variables in different measurement items.

Testing the model in two subsamples raised insights into how different relationship characteristics may influence relationships between buyers' support, farmers' investments and performance. For instance, the relationship between technical and managerial support and investment capacity and the relationship between performance in production and quality and investment requirements are significant only in the subsample of finishers. On the one hand, these findings corroborate evidence that buyers' support that includes providing inputs, which is the case in the sample of finishers, improves the farmers' investment capacity. On the other hand, our results suggest that buyers, in their decision making on investment requirements, would only be concerned with the performance of farmers to whom they provide the main inputs. To our knowledge, this is the first study providing such an insight.

\subsection{Management implications}

This study raises useful management implications. Improving quality at the farming stage is an important step in meeting consumer and costumer requirements and enabling these chains to maintain and further access high quality markets. In the BPC, processors usually make large investments and spend considerable resources to maintain support policies. This includes, for instance, maintaining a team of technicians, financing technical visits and training programs, information systems, and, in many cases, producing and providing inputs to be used by the farmers. Improving productivity increases the returns on these investments enabling these chains to further compete on costs. Therefore, buyers may further collaborate with farmers aiming to improve their investment behaviour and performance.

For instance, piglet farmers who are not provided with feed and sows do not perceive a direct influence of the support offered by buyers on their investment capacity. Although further research is needed to confirm this assumption, it might be valuable for buyers examining how effective their support services (i.e. not including input provision) are in enabling farmers to make investments. Such examination may allow for fine tuning these services (e.g. administrative support in credit; technical assistance). In this regard, buyers could also consider providing farmers with training, including demonstrating how improvements in agricultural and management practices can enhance the farmer's investment capacity.

Buyers and farmers would also benefit from increasing the information exchange in transactions in which buyers do not provide piglet farmers with critical inputs. As discussed above, the results suggest that buyers do not use information on farmers' performance to decide on investment requirements in these transactions. However, analysing productivity and quality, and assessing the agricultural practices and facilities the piglet farmers use may enable these buyers to refine their technical recommendations. Piglet farmers in turn may use these recommendations to improve agricultural practices and decision making on investments aimed at enhancing their productivity and the quality of the pigs they deliver to buyers.

In the finisher model, the results indicate that farmers perceive that investment capacity influences only their financial performance. Therefore, buyers could consider providing finishers with further information 
that relates farm investments to improved productivity and quality. Likewise, finishers could increase their focus on quality in their management practices. This could especially help strengthen the view on quality in buyer-farmer interactions and enhance the performance of farmers and the entire supply chain. Table 4 summarizes the main management implications for buyers and farmers in the BPC.

\subsection{Limitations}

The present study is not without its limitations. Firstly, the SEM model tests the hypothesis from a farmer perspective. Future studies could include the buyers' perspectives on how support policies influence farmer performance and investments. Secondly, the construct on managerial and technical support provided by buyers included only items related to services. However, the results suggest that differences in resource allocation matter when examining the relationships between buyers' support, investment capacity, investment requirements and performance. Further research testing the proposed model for differences in terms of provision of inputs, using a single type of farmer (i.e. piglet farmer) would provide more refined insights into how support provided by buyers influences farmers' investments and performance (Mishra et al., 2016). Thirdly, the study presents limitations concerning the specification of the SEM model. The factor loadings of BS1 and BS5 referring, respectively, to support in credit arrangements and technical assistance, are below the commonly acceptable threshold (Hair et al., 2019). However, these mechanisms are important and typical support services used in the Brazilian pork sector. Moreover, the Cronbach's alpha of the construct reached acceptable indexes in the three models. Hence, we considered it important to maintain these items in the model to provide useful insights for improvements in support policies. Other limitation concerning the SEM model refers to the subsamples of piglet farmers and finishers that failed to fully meet the goodness of fit measures. We recognize that this limitation may prevent us from drawing strong conclusions from the results obtained in these subsamples. However, these models provided interesting indications on how differences concerning support mechanisms may influence farmers' investments and performance. Future studies using a more refined sampling design may improve both factor loadings and goodness of fit measures.

Fourthly, the sample includes farmers that produce in different transactional contexts (i.e. to different types of buyers). Each context has specific characteristics that may constrain the support policies of buyers and their effectiveness. For instance, MIs very often use informal contracts in transactions with piglet farmers and provide technical support in a kind of 'on demand basis'. In Coops the relationship with farmers is twofold. Firstly, the farmer is a cooperative member who participates, to some degree, in the decision making and control of the organisation. Thus, the production contract is an additional relationship covering only the supply of agricultural inputs (e.g. piglets or finished pigs). This twofold relationship raises specific implications concerning the enforcement of transaction requirements (Cechin et al., 2013) that may also influence the support that cooperatives provide to farmers. Finally, compared to other types of buyers, IOFs use stricter mechanisms on resource allocation, such as input-providing contracts, in their relationship with farmers at all production stages. In this study, the limited size of the subsamples prevented us from controlling for differences related to coordination policies in distinct transactional contexts. Future studies could address these peculiarities.

Table 4. Management implications.

\begin{tabular}{ll}
\hline Chain actors & Main implications \\
\hline Buyers & Improvement of support policies concerning investments and performance of piglet farmers. \\
& Strengthening of the view on quality in relationships with finishers. \\
Piglet farmers & Increase of information exchange on performance with buyers. \\
Finishers & Strengthening the view on quality in management practices. \\
\hline
\end{tabular}


Lastly, the sample is geographically concentrated in the south of Brazil. In this region small farms - for swine and grain production - are prevalent and large-scale systems co-exist. In the mid-west, greater land areas and more efficient logistics structures can be found. These conditions enable chain actors to obtain inputs at lower costs than in the south. Moreover, pigs are typically produced in modern large-scale farms. Research comparing the influence of buyers' support on farmer performance and investments in the south and the mid-west would provide interesting insights for theoretical and management purposes.

\section{Supplementary material}

Supplementary material can be found online at https://doi.org/10.22434/IFAMR2020.0124

Table S1. Means in the full sample and subsamples - piglet farmers/finishers.

\section{References}

Bahlmann, J. and A. Spiller. 2009. The effect of institutional innovations on food chain governance: a case study on the shifting role of the German QS system from certification to supply chain coordination. Journal on Chain and Network Science 9(2): 89-103.

Bellemare, M.F. 2010. Agricultural extension and imperfect supervision in contract farming: evidence from Madagascar. Agricultural Economics 41: 507-517.

Bellemare, M.F. and J.R. Bloem. 2018. Does contract farming improve welfare? A review. World Development 112: $259-271$.

Brazilian Association of Animal Protein (ABPA). 2019. Annual report. ABPA, São Paulo, SP, Brazil.

Briones, R.M. 2015. Small farmers in high-value chains: binding or relaxing constraints to inclusive growth? World Development 72: 42-52.

Cechin, A., J. Bijman, S. Pascucci, D. Zylbersztajn and O. Omta. 2013. Quality in cooperatives versus investor-owned firms: evidence from broiler production in Paraná, Brazil. Managerial and Decision Economics 34: 230-243.

Cho, E. and S. Kim. 2015. Cronbach's coeficient alpha: well known but poorly understood. Organizational Research Methods 18(2): 207-230.

Coronado, J.J.A., J. Bijman, O. Omta and A.O. Lansink. 2010. Relationship characteristics and performance in fresh produce supply chains: the case of the Mexican avocado industry. Journal on Chain and Network Science 10(1): 1-15.

De Barcellos, M.D., M.S. Saab, F.A. Pérez-Cueto, M.G. Perin, M.F. Neves and W. Verbeke. 2011. Pork consumption in Brazil: challenge and opportunities for the Brazilian pork production chain. Journal on Chain and Network Science 11(2): 99-113.

Dries, L. 2015. The determinants of resource-providing contracts: case-study of the polish dairy sector. Review of Agricultural and Applied Economics 1: 25-34.

Dries, L., E. Germenji, N. Noev and J.F.M. Swinnen. 2009. Farmers, vertical coordination, and the restructuring, of dairy supply chains in Central and Eastern Europe. World Development 37(11): 1742-1758.

Falkowsky, J. 2012. Vertical coordination, access to capital, and producer loyalty in the Polish dairy sector. Agricultural Economics 43: 155-164.

Field, A. 2013. Discovering statistics using IBM SPSS statistics, $4^{\text {th }}$ edition. Sage, Newbury Park, CA, USA.

Gellynck, X. and A. Molnar. 2009. Chain governance structures: the European traditional food sector. British Food Journal 111(8): 762-775.

Ghosh, M. and G. John. 1999. Governance value analysis and marketing strategy. Journal of Marketing 63: 131-145.

Grande, J., E.L. Madsen and O.J. Borch. 2011. The relationship between resources, entrepreneurial orientation and performance in farm-based ventures. Entrepreneurship and Regional Development 23(3-4): 89-111.

Hair, J.F., J.J. Risher, M. Sarstedt and C.M. Ringle. 2019. When to use and how to report the results of PLSSEM. European Business Review 31(1): 2-24. 
Hair, J.F., W.C. Black., B.J. Babin and R.E. Anderson. 2010. Multivariate data analysis, $7^{\text {th }}$ edition. Prentice Hall, Hoboken, NJ, USA.

Handschuch, C., M. Wollni and P. Villalobos. 2013. Adoption of food safety and quality standards among Chilean raspberry producers - do smallholders benefit? Food Policy 40: 64-73.

Heyder, M., T. Hollmann-Hespos and L. Theuvsen. 2010. Agribusiness firm reactions to regulations: the case of investments in traceability systems. International Journal on Food System Dynamics 1(2): 133-142.

Hobbs, J.E. and L.M. Young. 2000. Closer vertical co-ordination in agri-food supply chains: a conceptual framework and some preliminary evidence. Supply Chain Management: an International Journal 5(3): 31-143.

Hooper, D., J. Coughlan and M. Mullen. 2008. Structural equation modelling: guidelines for determining model fit. Electronic Journal of Business Research Methods 6(1): 53-60.

Key, N. 2013. Production contracts and farm business growth and survival. Journal of Agricultural and Applied Economics 45(2): 277-293.

Key, N. and W. McBride, 2008. Do production contracts raise farm productivity? An instrumental variables approach. Agricultural and Resource Economics Review 37(2): 176-187.

Key, N. and W. McBride. 2003. Production contracts and productivity in the U.S. hog sector. American Journal of Agricultural Economics 85(1): 121-133.

Kresting, S. and M. Wollni. 2012. New institutional arrangements and standard adoption: evidence from small-scale fruit and vegetable farmers in Thailand. Food Policy 37: 452-462.

Labajova, K., H. Hansson, M. Asmild, L., Göransson, L., C.-J. Lagerkvist and M. Neil. 2016. Multidirectional analysis of technical efficiency for pig production systems: the case of Sweden. Livestock Science 187: $168-180$.

Lowry, P.B. and J. Gaskin. 2014. Partial least squares (PLS) structural equation modeling (SEM) for building and testing behavioral causal theory: when to choose it and how to use it. IEEE Transactions on Professional Communication 57(2): 123-146.

Lu, H., J.H. Trienekens, S.W.F. Omta and S. Feng. 2010. Guanxi networks, buyer-seller relationships, and farmers participation in modern vegetable markets in China. Journal of International Food \& Agribusiness Marketing 22: 70-93.

Lu, H., S. Feng, J.H. Trienekens and S.W.F. Omta. 2008. Performance in vegetable supply-chains: the role of Guanxi networks and buyer-seller relationships. Agribusiness 24(2): 253-274.

Maertens, M. and K. Vande Velde, K. 2017. Contract-farming in staple food chains: the case of rice in Benin. World Development 95: 73-87.

Martinez, S.W. 2012. Pork quality and the role of marketing contracts: a case study of the US pork industry. British Food Journal 114(3): 302-317.

Martins, F.M., J.H. Trienekens and O. Omta. 2017a. Differences in quality governance, the case of the Brazilian pork chain. British Food Journal 119(12): 2837-2850.

Martins, F.M., J.H. Trienekens and O. Omta. 2017b. Governance structures and coordination mechanisms in the Brazilian pork chain-diversity of arrangements to support the supply of piglets. International Food and Agribusiness Management Review 20(4): 511-532.

Martins, F.M., J.H. Trienekens and O. Omta. 2019. Implications of horizontal and vertical relationships on farmers performance in the Brazilian pork industry. Livestock Science 228: 161-169.

Ménard, C. 2004. The economics of hybrid organizations, Journal of Institutional and Theoretical Economics 160(3): 345-376.

Ménard, C. and E. Valceschini. 2005. New institutions for governing the agri-food industry. European Review of Agricultural Economics 32(3): 421-440.

Miele, M. and P.D. Waquil. 2007. Estrutura e dinâmica dos contratos na suinocultura de Santa Catarina: um estudo de casos múltiplos. Estudos Econômicos 37(4): 817-847.

Mishra, A.K., A. Kumar, P.K. Joshi and A. D'Souza. 2016. Impact of contracts in high yielding varieties seed production on profits and yield: the case of Nepal. Food Policy 62: 10-121.

Otsuka, K., Y. Nakano and K. Takahashi. 2016. Contract farming in developed and developing countries. Annual Review of Resource Economics 8: 353-376. 
Plaggenhoef, W. 2007. Integration and self regulation of quality management in Dutch agri-food supply chains - a cross chain analysis of the poultry meat, the fruit and vegetable and the flower and potted plant chains. PhD-thesis, Wageningen University and Research Centre, Wageningen, the Netherlands.

Raynaud, E., L. Sauvee and E. Valceschini. 2005. Alignment between quality enforcement devices and governance structures in the agro-food vertical chains. Journal of Management and Governance 9: 47-77.

Rindfleisch, A. and J.B. Heide. 1997. Transaction cost analysis: past, present, and future applications. Journal of Marketing 61(4): 30-54.

Schulze, B., A. Spiller and L. Theuvsen. 2007. A broader view on vertical coordination: lessons from German pork production. Journal on Chain and Network Science 7(1): 35-53.

Swineen, J.F.M. and M.V. Maertens. 2007. Globalization, privatization, and vertical coordination in food value chains in developing and transition countries. Agricultural Economics 37(1): 89-102.

Tomarken, J.A. and N.G. Waller. 2005. Structural equation modeling: strengths, limitations, and misconceptions. Annual Review of Clinical Psychology 1: 31-65.

United States Department of Agriculture (USDA). 2019. EU and UK production, supply and distribution (PSD) datasets and 'Brexit'. USDA Foreign Agricultural Service, Washington, DC, USA. Available at: http://apps.fas.usda.gov/psdonline/psdHome.aspx

Wever, M., N. Wognum, J. Trienekens and O. Omta. 2010. Alignment between chain quality management and chain governance in EU pork supply chains: a transaction-cost-economics perspective. Meat Science 84(2): 228-237.

Williamson, O.E. 1991. Comparative economic-organization - the analysis of discrete structural alternatives. Administrative Science Quarterly 36(2): 269-296.

Williamson, O.E. 2008. Outsourcing: transaction cost economics and supply chain management. Journal of Supply Chain Management 44(2): 5-16.

Williamson, O.E. 2010. Transaction cost economics: the natural progression. Journal of Retailing 86(3): 215-226.

Wu, A., Z. Wang and S. Chen, S. 2017. Impact of specific investments, governance mechanisms and behaviors on the performance of cooperative innovation projects. International Journal of Project Management 35: 504-515.

Zylbersztajn, D. and E.M.M.Q. Farina. 1999. Strictly coordinated food-systems: exploring the limits of the Coasian firm. International Food and Agribusiness Management Review 2(2): 249-265. 
